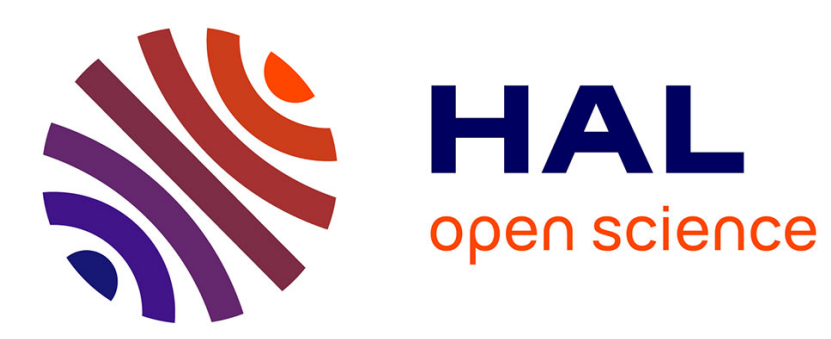

\title{
Exotic molecular and halo states in ${ }^{12,14} \mathrm{Be}$
}

M. Freer, N.A. Orr, M. Labiche, F.M. Marqués, J.C. Angélique, L. Axelsson, B. Benoit, U. Bergmann, M J G. Borge, W N. Catford, et al.

\section{To cite this version:}

M. Freer, N.A. Orr, M. Labiche, F.M. Marqués, J.C. Angélique, et al.. Exotic molecular and halo states in ${ }^{12,14}$ Be. International Conference on Exotic Nuclei and Atomic Masses ENAM 98, Jun 1998, Bellaire, United States. pp.314-318, 10.1063/1.57333 . in2p3-00009571

\section{HAL Id: in2p3-00009571 https://hal.in2p3.fr/in2p3-00009571}

Submitted on 12 Oct 1999

HAL is a multi-disciplinary open access archive for the deposit and dissemination of scientific research documents, whether they are published or not. The documents may come from teaching and research institutions in France or abroad, or from public or private research centers.
L'archive ouverte pluridisciplinaire HAL, est destinée au dépôt et à la diffusion de documents scientifiques de niveau recherche, publiés ou non, émanant des établissements d'enseignement et de recherche français ou étrangers, des laboratoires publics ou privés. 

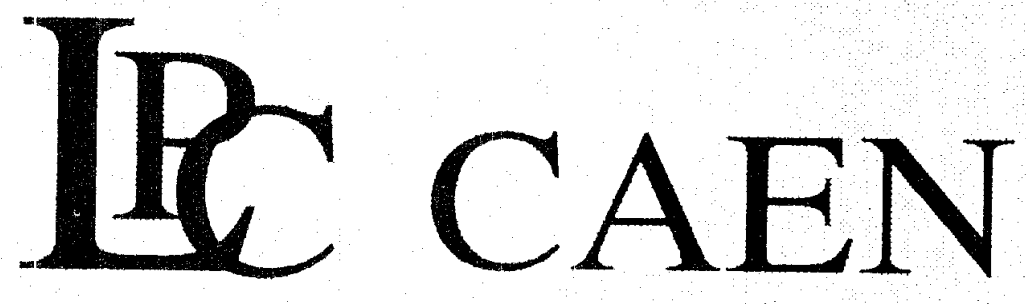

Laboratoire de Physique Corpusculaire ISMRA - Boulevard Maréchal Juin - 14050 CAEN CEDEX - FRANCE

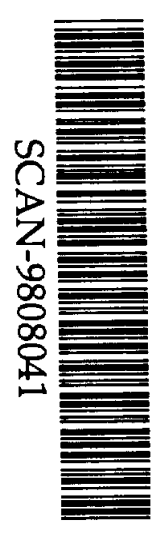

\section{Exotic Molecular and Halo States in ${ }^{12,14} \mathrm{Be}$}

M. Freer, N.A: Orr, M. Labiche, F. M. Marqués, J.C. Angélique, L. Axelsson, B. Benoit, U. Bergmann, MJ.G. Borge,

W.N. Catford, S.P.G. Chappell, N.M. Clarke, G. Costa, N. Curtis, A. D'Arrigo, F. D'Oliviera, E. de Goes Brennard, O. Dorvaux, B.R. Fulton, G. Gardina, C. Gregori, S. Grévy, D. Guillemaud-Mueller, F. Hanappe, B. Heusch, B. Jonson,

G. Kelly, C. Le Brun, S. Leenhardt, M. Lewitowicz, K. Markenroth, M. Motta, A.C. Mueller, J. T. Murgatroyd, T. Nilsson, A. Ninane, G. Nyman, I. Piqueras, K. Riisager, M.G. Saint-Laurent, F. Sarazin, S. Singer, O. Sorlin, L. Stuttgé, D.L. Watson

Contribution to ENAM 98 - "Second International Conference on Exotic Nuclei and Atomic Masses”, 23-27 June 1998, Michigan, USA

INSTITUT NATIONAL

DE PHysiqLe NUCleaire et de PHysique des PaRticlles

CENTRE NATIONAL DE LA RECHERCHE SCIENTIFIQUE

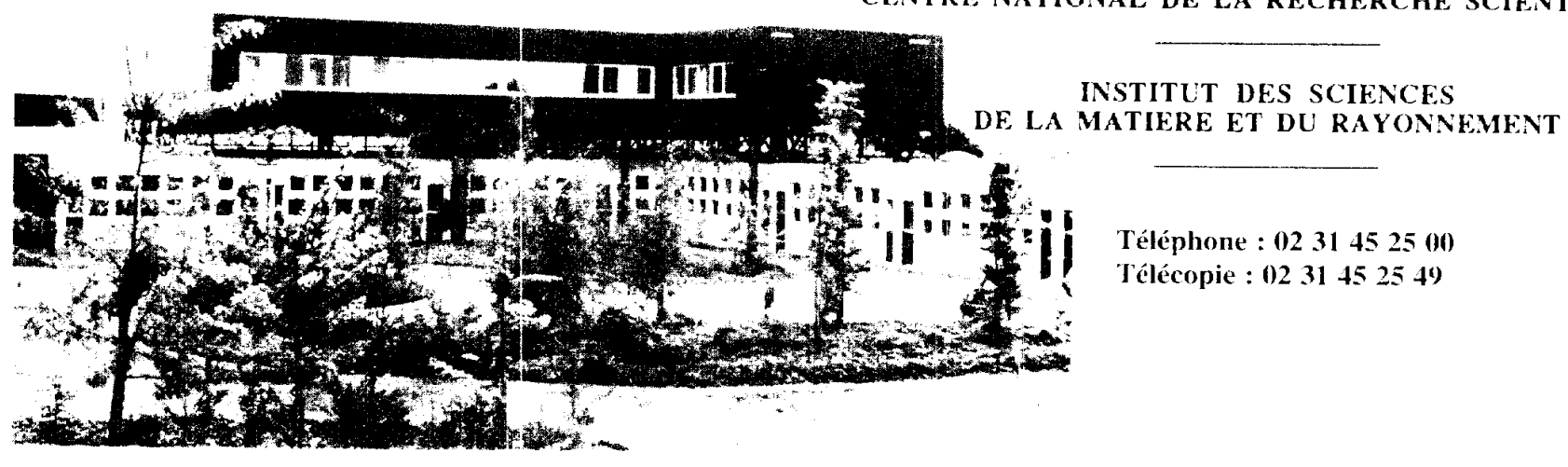




\title{
Exotic Molecular and Halo States in ${ }^{12,14} \mathrm{Be}$
}

M. Freer ${ }^{a, b}$, N.A. Orr ${ }^{b}$, M. Labiche ${ }^{b}$, F.M. Marqués ${ }^{b}$, J.C. Angélique $^{b}$, L. Axelsson ${ }^{c}$, B. Benoit ${ }^{d}$, U. Bergmann ${ }^{e}$, M.J.G. Borge ${ }^{j}$, W.N. Catford ${ }^{f}$, S.P.G. Chappell ${ }^{g}$, N.M. Clarke ${ }^{a}$, G. Costa ${ }^{h}$, N. Curtis $^{f}$, A. D'Arrigo ${ }^{d}$, F. D'Oliviera ${ }^{m}$, E. de Goes Brennard ${ }^{d}$, O. Dorvaux $^{h}$, B.R. Fulton ${ }^{a}$, G. Gardina ${ }^{i}$, C. Gregori ${ }^{j}$, S. Grévy ${ }^{b, k}$, D. Guillemaud-Mueller ${ }^{k}$, F. Hanappe ${ }^{d}$, B. Heusch ${ }^{h}$, B. Jonson ${ }^{c}$, G. Kelly $^{l}$, C. Le Brun ${ }^{b}$, S. Leenhardt ${ }^{k}$, M. Lewitowicz ${ }^{m}, \mathrm{~K}$. Markenroth $^{c}$, M. Motta ${ }^{i}$, A.C. Mueller ${ }^{k}$, J.T. Murgatroyd ${ }^{a}$, T.

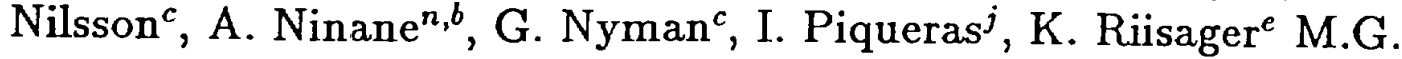
Saint Laurent ${ }^{m}$, F. Sarazin ${ }^{m, b}$, S. Singer ${ }^{a}$, O. Sorlin ${ }^{k}$, L. Stuttgé ${ }^{h}$, D.L. Watson ${ }^{o}$

achool of Physics and Astronomy, University of Birmingham, Birmingham B15 2TT, U.K.

${ }^{b}$ LPC-ISMRA, Bd Marechal Juin, 11050 Caen Cedex, France.

${ }^{c}$ Fysiska Institutionen, Chalmers Tekniska Högskola, S-412 96 Göteborg, Sweden.

'Universite Libre de Bruxelles, CP 226, B-1050 Bruxelles, Belgium.

'Det Fysiske Institut, Aarhus Universitet, DK 8000 Aarhus C, Denmark.

${ }^{f}$ Department of Physics, University of Surrey, Guildford, Surrey, GU2 $5 X H, U . K$.

Department of Nuclear Physics, University of Oxford, Keble Road, Oxford OXI $3 R H, U . K$. ${ }^{h}$ IReS, B.P.28, F-67097 Strasbourg Cedex, France.

'Departimento di Fisica, Università di Messina, Salita Sperone 31, I-98166 Messina, Italy.

jInstituto Estructura de la Materia, CSIC, E-28006 Madrid, Spain.

kInstitut de Physique Nucléaire 91106 Orsay Cedex, France.

'School of Sciences, Stuffordshire Univerisity, College Road, Stoke-on-Trent, ST\} 2DE, U. K. "'GANIL, BP 5027, 14076 Caen Cedex, France.

nInstitut de Physique, Universite Catholique de Louvain, B-1928 Louvain-la-Neuve, Belgium. - Department of Physics, University of York, York, YOI 5DD, U. K.

\begin{abstract}
The two nuclei ${ }^{12} \mathrm{Be}$ and ${ }^{14} \mathrm{Be}$ have been studied using breakup reactions on $\mathrm{p},{ }^{12} \mathrm{C}$ and ${ }^{208} \mathrm{~Pb}$ targets. The decay of ${ }^{12} \mathrm{Be}$ into two helium clusters $\left({ }^{6} \mathrm{He}+{ }^{6} \mathrm{He}\right.$ and ${ }^{1} \mathrm{He}+{ }^{8} \mathrm{He}$ ) was observed from a series of excited states between 10 and $25 \mathrm{MeV}$, with spins in the range $4^{+}$to $8^{+}$. The single neutron angular distributions for ${ }^{14} \mathrm{Be}$ exhibit the narrow forward peak characteristic of a halo. The widths of these distributions in coincidence with ${ }^{12} \mathrm{Be}$ fragments are $\Gamma_{L}=78 \pm 6$ and $80 \pm 1 \mathrm{MeV} / \mathrm{c}$ for breakup on carbon and lead.
\end{abstract}

Contribution to ENAM98 - "Second Intemational Conference on Exotic Nuclei and Atomic Masses", 23-27 June 1998, Michigan, USA 

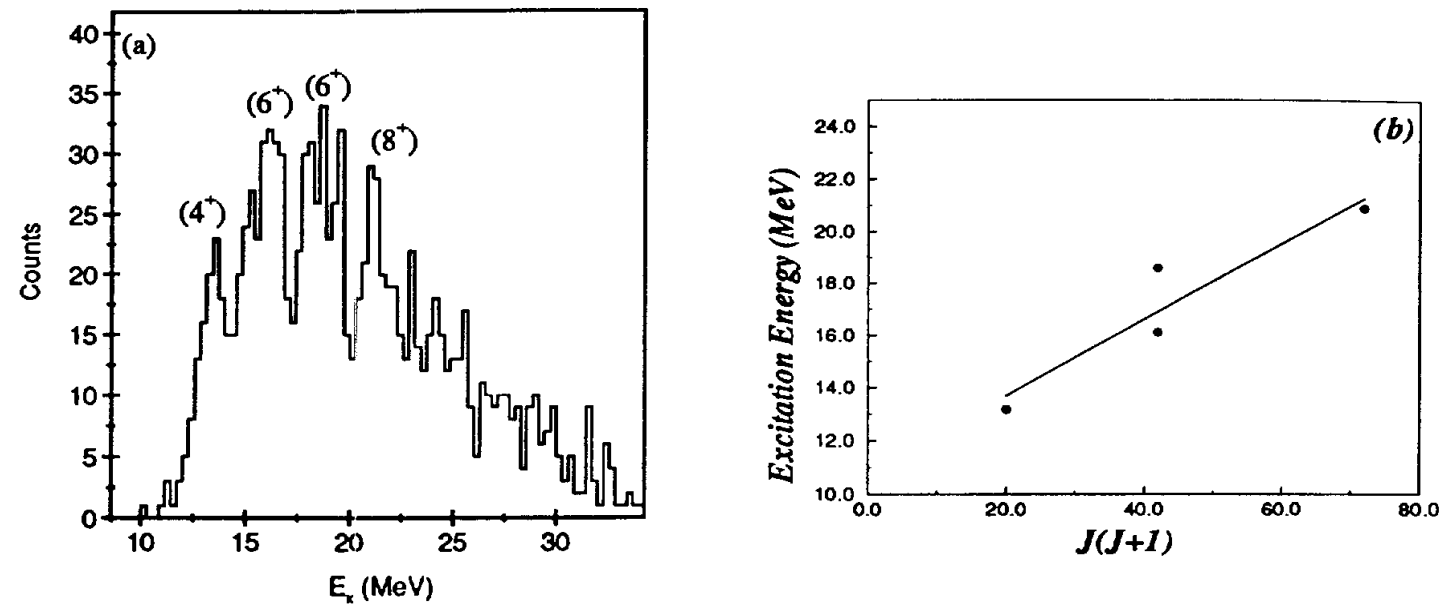

FIGURE 1. (a) ${ }^{12} \mathrm{Be}$ excitation energy spectrum for ${ }^{6} \mathrm{He}+{ }^{6} \mathrm{He}$ coincidences, (b) the energy-spin systematics of the breakup states.

the case of the ${ }^{14} \mathrm{Be}$ studies, measurements were carried out on secondary reaction targets of carbon and lead $\left(\bar{E}_{14 B e}=35 \mathrm{MeV} /\right.$ nucleon at target mid-point) in an attempt to disentangle the effects of nuclear and Coulomb induced breakup. For the ${ }^{12} \mathrm{Be}$ measurements, ${ }^{12} \mathrm{C}$ and $\left(\mathrm{CH}_{2}\right)_{n}$ target foils were used, with beam tracking and time-of-flight measurement provided by two parallel plate avalanche counters. The breakup of the ${ }^{12} \mathrm{Be}$ nucleus into two helium fragments was detected in an array of ten $\mathrm{Si}-\mathrm{CsI}$ telescopes placed around the beam axis. The silicon elements were two dimensional position sensitive detectors (2DPSDs), proving a measurement of the angle of the incident particles with a resolution of better than $0.5^{\circ}$. The telescopes provided a clean identification of the ${ }^{4} \mathrm{He},{ }^{6} \mathrm{He}$ and ${ }^{8} \mathrm{He}$ nuclei of interest, and a measurement of the energy with a resolution of $1.5 \%$. For the ${ }^{14} \mathrm{Be}$ experiment the charged reaction products were again detected using the 10 element position sensitive Si-CsI array with one of the elements placed at zero degrees. Neutrons were detected using the 99 modules of the DEMON array. A staggered arrangement

\begin{tabular}{|l|l|l|}
\hline Reaction & Target & $\sigma(\mathrm{mb})$ \\
\hline \hline $\mathrm{p}\left({ }^{12} \mathrm{Be}^{6} \mathrm{He}^{6} \mathrm{He}\right) \mathrm{p}$ & $\left(\mathrm{CH}_{2}\right)_{\mathrm{n}}$ & $0.76(0.05)$ \\
${ }^{12} \mathrm{C}\left({ }^{12} \mathrm{Be},{ }^{6} \mathrm{He}^{6} \mathrm{He}\right)^{12} \mathrm{C}$ & $\left(\mathrm{CH}_{2}\right)_{\mathrm{n}}$ & $0.26(0.06)$ \\
${ }^{12} \mathrm{C}\left({ }^{12} \mathrm{Be},{ }^{6} \mathrm{He}^{6} \mathrm{He}\right)^{12} \mathrm{C}$ & ${ }^{12} \mathrm{C}$ & $0.28(0.04)$ \\
$\mathrm{p}\left({ }^{12} \mathrm{Be},{ }^{4} \mathrm{He}^{8} \mathrm{He}\right) \mathrm{p}$ & $\left(\mathrm{CH}_{2}\right)_{\mathrm{n}}$ & $2.91(0.06)$ \\
${ }^{12} \mathrm{C}\left({ }^{12} \mathrm{Be}^{4}{ }^{4} \mathrm{He}^{8} \mathrm{He}\right){ }^{12} \mathrm{C}$ & $\left(\mathrm{CH}_{2}\right)_{\mathrm{n}}$ & $1.62(0.11)$ \\
${ }^{12} \mathrm{C}\left({ }^{12} \mathrm{Be}^{4} \mathrm{He}^{8} \mathrm{He}\right)^{12} \mathrm{C}$ & ${ }^{12} \mathrm{C}$ & $0.79(0.07)$ \\
\hline
\end{tabular}

TABLE 1. ${ }^{12}$ Be breakup reaction cross sections. 


\begin{tabular}{|c|c|c|c|c|}
\hline \multirow{2}{*}{ Channel } & \multicolumn{2}{|c|}{$\sigma_{\text {telescope }}[\mathrm{mb}]$} & \multicolumn{2}{c|}{$\Gamma_{\mathrm{n}}[\mathrm{MeV} / \mathrm{c}]$} \\
\cline { 2 - 5 } & $\mathrm{C}$ & $\mathrm{Pb}$ & $\mathrm{C}$ & $\mathrm{Pb}$ \\
\hline \hline${ }^{12} \mathrm{Be}$ & $460 \pm 40$ & $2300 \pm 400$ & - & - \\
${ }^{12} \mathrm{Be}+\mathrm{n}$ & - & - & $78 \pm 6$ & $80 \pm 1$ \\
${ }^{11} \mathrm{Be}$ & $85 \pm 15$ & - & - & - \\
${ }^{10} \mathrm{Be}$ & $145 \pm 20$ & - & - & - \\
${ }^{10} \mathrm{Be}+\mathrm{n}$ & - & - & $119 \pm 44$ & - \\
\hline
\end{tabular}

TABLE 2. Preliminary results for the breakup of ${ }^{14} \mathrm{Be}$ on $\mathrm{C}$ and $\mathrm{Pb}$ targets. The single neutron angular distributions have been characterized in terms of a Lorentzian distribution.

for the neutron detectors was chosen so as to maximize the coverage at forward angles whilst minimizing the effects of cross talk (both geometrically and in the off-line analysis).
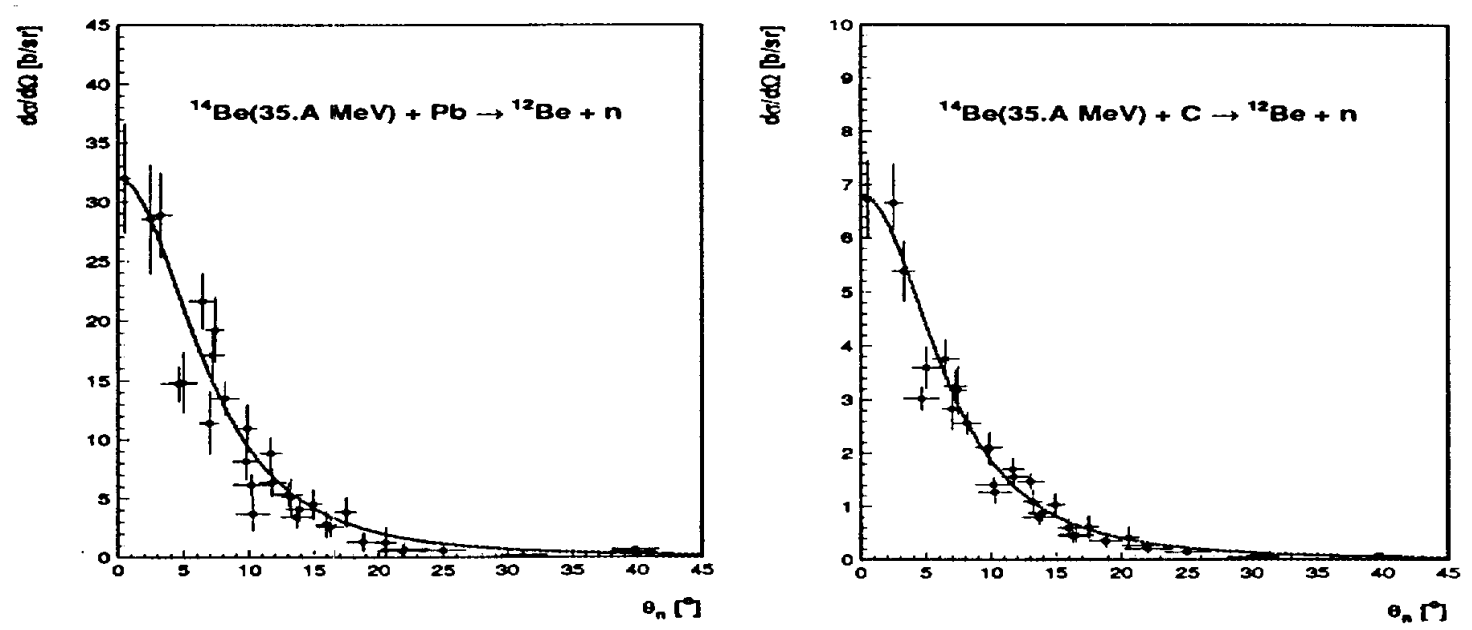

FIGURE 2. Single neutron angular distributions for the breakup of ${ }^{14} \mathrm{Be}\left(E_{n}=10\right.$ to $\left.100 \mathrm{MeV}\right)$.

\section{A ${ }^{12}$ Be breakup}

The Q-values for the reactions ${ }^{12} \mathrm{C}\left({ }^{12} \mathrm{Be},{ }^{\mathrm{x}} \mathrm{He}{ }^{\mathrm{y}} \mathrm{He}\right){ }^{12} \mathrm{C}$ and $\mathrm{p}\left({ }^{12} \mathrm{Be},{ }^{\mathrm{x}} \mathrm{He} \mathrm{y}^{y} \mathrm{He}\right) \mathrm{p}$ were calculated from the energies of the two detected helium nuclei and the energy of the undetected recoil-like particle inferred from the measured momenta of the beam and detected reaction products. In the case of the $\left(\mathrm{CH}_{2}\right)_{n}$ target this technique was able to resolve the reactions taking place on the carbon and hydrogen. The cross 
sections for the various reactions are given in Table 1. Selecting events identified with peaks in the $\mathrm{Q}$-value spectra for the above reactions, it is possible to calculate the excitation energy, or invariant mass, of the ${ }^{12} \mathrm{Be}$ nucleus prior to decay using the relationship

$$
E_{x}=\frac{1}{2} \mu v_{r e l}^{2}+Q_{b r u}
$$

where $v_{r e l}$ is the relative velocity of the two breakup fragments, $\mu$ the reduced mass and $Q_{b u}$ the breakup Q-value, which for the ${ }^{6} \mathrm{He}+{ }^{6} \mathrm{He}$ and ${ }^{8} \mathrm{He}+{ }^{4} \mathrm{He}$ channels is 10.11 and $8.95 \mathrm{MeV}$ respectively. Figure $1 \mathrm{a}$ shows the ${ }^{12} \mathrm{Be}$ excitation energy spectrum for decays into two ${ }^{6} \mathrm{He}$ nuclei. These states, which span the excitation energy region 10 to $25 \mathrm{MeV}$, are the first definitive evidence for the $2 \alpha-4 \mathrm{n}$, molecular cluster structure in this nucleus [5]. Angular correlation measurements of the breakup products indicate that the states may be associated with spins from $4^{+}$to $8^{+}$, and the inferred excitation energy-spin sequence appears to be consistent with a rotational band with a large moment of inertia (Figure $1 \mathrm{~b}$ ).

\section{B ${ }^{14} \mathrm{Be}$ breakup}

The ${ }^{14} \mathrm{Be}$ reaction cross sections derived from the telescope data confirm that the two-neutron removal reaction channel is dominant, as seen in an earlier experiment [6]. The single neutron angular distributions (shown in Figure 2) exhibit the narrow, forward peaked form characteristic of a halo. Interestingly the characteristic widths of the distributions for the two targets are very similar and thus may suggest, as in the case of ${ }^{11} \mathrm{Li}[7]$, the existence of a very low lying state in ${ }^{13} \mathrm{Be}$. The analysis of the ${ }^{12} \mathrm{Be}+\mathrm{n}$ invariant mass spectrum, presently underway, should shed further light on this conjecture. The ${ }^{12} \mathrm{Be}+\mathrm{n}+\mathrm{n}$ invariant mass spectrum is being investigated in parallel with the objective of extracting the low-lying dipole strength function, $d B(E 1) / d E_{x}$. The two-neutron correlations - relative momenta and correlation function, $C(q)$ - are also under analysis, with the present effort concentrating on inclusion of the effects of neutron-neutron final state interactions. The results of these analyses when compared with realistic three-body models are expected to provide important insights into the halo structure of ${ }^{14} \mathrm{Be}$.

[1] K. Ikeda, Supp]. Prog. Physics (Japan) Extra Numbers, 464 (1968).

[2] S. Yang, et al., Chem. Phys. Letts. 144, 431 (1988).

[3] D.H. Wilkinson, Nucl. Phys. A 452, 296 (1986).

[4] W. von Oertzer, Z. Phys. A 354, 249 (1996), Z. Phys. A 357, 355 (1997).

[5] A.A. Korshinnikov, et al., Phys. Letts. B 343, 53 (1995).

[6] K. Riisager et all, Nucl. Phys. A540, 365 (1992).

[7] F. Barranco et al., Phys. Lett. B319, 387 (1993). 


\section{INTRODUCTION}

The stability of the $\alpha$-cluster has a strong influence on the structure of light nuclei and has spawned an industry devoted to the understanding of the role of clustering in s-d shell nuclei dating from the early 1960's when heavy-ion beams were first exploited. The advent of radioactive beams has also revealed clustering in light, neutron-rich nuclei, in the guise of the halo, where the nucleus is composed of a core and valence halo neutrons, and the molecular type cluster states composed of $\alpha$-particles bound by the valence neutrons.

In the 1960's, Ikeda [1] developed a classification of clustering in light $A=4 n$, $\alpha$-conjugate nuclei, in which cluster structures appeared at, or close to, the decay threshold for the particular cluster partition. This scheme, which is on the whole verified by experimental observations, is based on the premise that to create the internal cluster structures an energy equivalent to the binding energy of the constituents is required. Thus systems that include weakly bound neutrons, e.g. ${ }^{11} \mathrm{Be}$ $\left(S_{n}=0.5 \mathrm{MeV}\right)$ and ${ }^{11} \mathrm{Li}\left(S_{2 n} \simeq 0.3 \mathrm{MeV}\right)$, should show strong clustering characteristics. Clustering is amplified in these systems by reduced centrifugal barriers for the weakly bound valence neutrons allowing a greater decoupling of the core and halo neutrons. The heaviest particle stable Be isotope, ${ }^{14} \mathrm{Be}\left(S_{2 n}=1.34 \pm 0.11\right.$ $\mathrm{MeV}$ ), is Borromean and is known to exhibit a two-neutron halo. In contrast to other halo systems, the configuration of the valence neutrons is expected to contain a significant d-wave admixture. Additionally, ${ }^{14} \mathrm{Be}$ is the heaviest two-neutron halo nucleus currently known. The investigation of ${ }^{14} \mathrm{Be}$, presented here, thus provides an opportunity to study the evolution of halo systems with binding energy, angular momentum and mass.

Another extreme manifestation of clustering is the formation of chain and ring structures composed of individual cluster units, such as $\alpha$-particles. Indeed there is some evidence for such structures in light nuclei. Similar arrangements have also been observed in atomic systems, for example carbon clusters [2] which are believed to be related to particular spectral lines in astronomical observations of stellar dust clouds. Another nuclear analogue of such phenomena are $\alpha$-ring and chain structures covalantly bonded by valence neutrons, predicted by Wilkinson [3], much as the binding of atomic molecules through the exchange of electrons. Von Oertzen [4] has characterized the structure of the sequence of Be isotopes ${ }^{9} \mathrm{Be}$ to ${ }^{11} \mathrm{Be}$ in terms of dinuclear $2 \alpha$-Xn structures, and certain carbon isotopes as trinuclear molecules. The present contribution reports a measurement of the $2 \alpha-4 \mathrm{n}$ cluster system ${ }^{12} \mathrm{Ee}$.

\section{EXPERIMENTAL MEASUREMENTS}

The secondary beams of ${ }^{12,14} \mathrm{Be}\left(\bar{E}_{12} \mathrm{Be}=31.5 \mathrm{MeV} /\right.$ nucleon, $i \approx 2.10^{4} \mathrm{pps}, \bar{E}_{14 \mathrm{Be}}$ $=41.3 \mathrm{MeV} /$ nucleon, $i \approx 10^{2} \mathrm{pps}$ ) were prepared from the fragmentation of an ${ }^{18} \mathrm{O}$ beam $(63 \mathrm{MeV} / \mathrm{nucleon})$ on a thick Be target using the LISE3 spectrometer. In 
